\title{
Participation of sex hormones in multifactorial pathogenesis of adolescent idiopathic scoliosis
}

\author{
Aleksandra Kulis ${ }^{1}$ - Anna Goździalska ${ }^{2}$ - Jagoda Drąg ${ }^{3}$ - Jerzy Jaśkiewicz ${ }^{2}$. \\ Malgorzata Knapik-Czajka ${ }^{3}$ - Ewa Lipik ${ }^{4}$ Daniel Zarzycki ${ }^{4}$
}

Received: 25 February 2015 / Accepted: 4 March 2015 /Published online: 25 March 2015

(C) The Author(s) 2015. This article is published with open access at Springerlink.com

\begin{abstract}
Purpose In order to verify the potential association between the aetiopathogenesis of adolescent idiopathic scoliosis (AIS) and the process of sexual maturation, we determined the concentrations of oestrogens in pre- and postmenarcheal girls affected by this condition. AIS, occurring mostly in pubescent girls, is one of the most frequent forms of faulty posture. Therefore, it was assumed that the multifactorial pathomechanism of AIS involves significant deficiency of oestrogens.

Methods The diagnosis of AIS was established on the basis of physical examination and analyses of radiograms. Concentrations of FSH, LH, oestrogens, progesterone, osteocalcin and RANKL were determined by ELISA. The activity of alkaline phosphatase (AP) was measured by kinetic method. The study included pre- and postmenarcheal girls with AIS and corresponding groups of scoliosis-free controls. Results In premenarcheal scoliotic girls, the levels of FSH, LH and oestradiol were lower; the levels of progesterone, oestrone and oestriol were higher; and the concentrations of
\end{abstract}

Jagoda Drag

jagoda.drag@gmail.com

1 Department of Physical Therapy, The University School of Physical Education, Krakow, Poland

2 Faculty of Health and Medical Science, Andrzej Frycz Modrzewski Krakow University, Krakow, Poland

3 Department of Analytical Biochemistry, Faculty of Pharmacy, Jagiellonian University Medical College, Krakow, Poland

4 Department of Orthopaedic-Rehabilitation, Jagiellonian University, University Hospital of Orthopaedic-Rehabilitation,

Zakopane, Poland oestrone and oestriol were similar compared to premenarcheal controls. Higher levels of RANKL, osteocalcin and AP were observed in premenarcheal adolescents with AIS compared to controls. The concentrations of FSH, LH, oestradiol, and progesterone in postmenarcheal girls with scoliosis were lower, oestrone were slightly lower and oestriol did not differ compared with the control group. Significantly higher levels of RANKL, osteocalcin and AP were observed in postmenarcheal scoliotic adolescents compared with controls. Conclusions There is an interdependence between the concentration of oestradiol and development of scoliosis. Determination of estradiol may have diagnostic value in the screening of spinal pathologies associated with AIS.

Keywords Oestrogens · Adolescent idiopathic scoliosis · Bone markers

\section{Introduction}

The increasing prevalence of faulty posture among children and adolescents is caused by an array of development-related factors, including low levels of physical activity and many metabolic disorders [1]. Despite a dynamic development of comprehensive diagnostic and correcting methods, the increasing prevalence of postural deformation still remains unchanged. Adolescent idiopathic scoliosis (AIS) is one of the most frequent forms of faulty posture $[2,3]$. This spinal deformation occurs mostly among pubescent girls [4]. Many authors emphasize multifactorial pathomechanism of scoliosis [5-8], and the involvement of genetic and epigenetic predispositions, and the influence of hormonal factors are widely accepted [6, 7, 9-15].

Although the exact aetiology and molecular mechanisms underlying the development of adolescent 
idiopathic scoliosis are still not fully understood, the concept of multifactorial pathomechanism in widely accepted. Furthermore, the involvement of, yet unidentified, genetic factors in the development of AIS is emphasized. The development of scoliosis is assumed to be associated with a sex-linked predominant gene with incomplete penetrance and variable expression. Although familial predisposition to scoliosis points unequivocally to genetic background of this condition, the exact mechanism of inheritance still has to be confirmed. The AIS-associated loci were identified on both autosomes [16-18] and the X chromosome [19]. Therefore, a polygenic inheritance model with incomplete penetrance and variable expression (DNA methylation) is postulated [3, 20, 21]. To confirm this hypothesis, the presence of the Carter effect in adolescent idiopathic scoliosis is observed. This effect suggests that males with AIS would need to inherit a greater number of susceptibility genes compared with females to develop the deformity. Males would also be more likely to transmit the disease to their children. This would support polygenic inheritance theory and greater prevalence of disease in adolescent girls with idiopathic scoliosis [22].

It is postulated that the development of AIS comprises of two stages: initial functional impairment of osteoblasts and osteoclasts, and the stage of actual spinal deformation $[6,10]$. The reasons for the above mentioned pathological changes are still a subject of research. The occurrence of AIS in girls is more frequent than in boys, especially during the pubescent period, before menarche [23]. The number of girls with scoliosis with Cobb angle greater than $10^{\circ}$ is twice as high as the number of boys with this condition, and the prevalence of deformations with Cobb angular values above $30^{\circ}$ is eight-fold higher among girls than boys [20]. The association between the progression of idiopathic scoliosis, gender, and age of sexual maturity has raised interest in oestrogenss, as hormones that can be potentially involved in AIS aetiopathogenesis [12, 24]. Although oestrogens do not constitute an etiological factor of AIS, they can influence the progression of spinal deformation, interacting with other factors modulating growth, biomechanics, and the structure of bones. Oestrogens repress osteoclastogenic cytokine production, including interleukine-6 (IL-6), interleukine-1 (IL-1), receptor activator of nuclear factor B ligand (RANKL) from immune cells and osteoblasts, increase osteoblast proliferation, decrease osteoblast and osteocyte apoptosis and induce osteoclast apoptosis [25, 26]. As scoliosis is frequently concomitant to decreased concentrations of oestrogens and delayed puberty, it has been hypothesized that oestrogen deficiency can play an important role in the multifactorial pathomechanism of AIS [27-29]. In order to verify potential association between the aetiopathogenesis of scoliosis and the process of sexual maturation, we determined the serum oestrogen, oestron, oestriol, progesterone, RANKL, osteocalcin concentrations and alkaline phosphatase activity of pre- and postmenarcheal girls with AIS.

\section{Material and methods}

The study included a group of girls treated at the Orthopedic-Rehabilitation University Hospital in Zakopane. The protocol of the study was approved by the Local Bioethical Committee and the legal guardians of all participating girls expressed their written informed consent for enrolling their children into the project. A total of 200 girls, aged between 11 and 14 years, were examined. They were divided into four groups of 50 girls each. The first (group I) comprised of premenarcheal girls with scoliosis (mean age 12.6 years), the second (group II) of postmenarcheal scoliosis patients (mean age 14.6 years), and the third and fourth were control groups of pre- (group III) and postmenarcheal (group IV) scoliosis-free subjects (mean age 12.4 and 13.8 years, respectively). Both the girls with scoliosis and healthy controls without spinal deformations were hospitalized at the Department of Orthopaedics. The enrollment criterion for groups I and II was scoliosis, and only girls with normal posture (however allowing trauma-related deformations) were qualified to the control groups.

The Cobb angle in all girls with scoliosis was greater than $15^{\circ}$. The diagnosis of idiopathic scoliosis was established on the basis of physical examination and antero-posterior (AP) radiograms performed every six months. All biochemical parameters were determined in blood sera obtained during routine diagnostic procedures. The samples were frozen and stored at $-80{ }^{\circ} \mathrm{C}$, until analysis. The blood samples from postmenarcheal girls were obtained two to three days following the last day of the menstrual period. Concentrations of hormones: FSH (EIA-1288, DRG International, Germany), LH (EIA1289, DRG International, Germany), estradiol (EIA2693, DRG International, Germany), estrone (EIA-4174, DRG International, Germany), estriol (EIA-3717, DRG International, Germany), progesterone (EIA-1561, DRG International, Germany), osteocalcin (EIA-3375, DRG International, Germany) and RANKL (K1016, Immundiagnostic AG, Germany) were determined by ELISA with commercially available kits and Microplate Reader Rayto RT 2100C, as described by Sambrook and Russel [30]. The activity of alkaline phosphatase was measured by kinetic method using a commercially available kit (92214, Biolabo, France). 


\section{Statistical analysis}

The results were subjected to statistical analysis with STAT ISTICA PL 10.0 software (StatSoft, Tulsa OK, United States). Statistical characteristics of continuous variables were presented as: arithmetic means, standard deviations (SD), and minimum and maximum values. Prior to analysis, we verified the normality of continuous variables distributions, and tested the homogeneity of their variances with the Levene's test. The hypothesis on the lack of differences between hormonal parameters of four studied groups was verified with two-way factorial ANOVA. Acceptable significance level was set at $p$ $<0.05$.

\section{Results}

We determined the levels of sex hormones, FSH, LH, oestrogens (oestradiol, oestrone, oestriol), and progesterone as well as osteocalcin, RANKL and alkaline phosphatase for all studied groups, i.e. in pre- and postmenarcheal girls with scoliosis and in pre- and postmenarcheal controls. Mean age of premenarcheal girls with scoliosis and premenarcheal controls amounted to 12.6 and 12.4 years, respectively, and mean ages of postmenarcheal scoliosis patients and postmenarcheal controls were equal to 14.6 and 13.8 years, respectively.

In premenarcheal girls with scoliosis the levels of FSH (88.6 \%; $p=0.167)$, LH $(95.8 \% ; p=0.646)$ and oestradiol $(38.8 \% ; p=0.000)$ were lower than in premenarcheal healthy girls. Higher levels of oestrone $(100.5 \% ; p=0.959)$, oestriol $(100.9 \% ; p=0.880)$ and progesterone $(108 \% ; p=0.394)$ were observed in premenarcheal adolescents with AIS, compared with control groups. The difference in oestrogen levels were statistically significant $(p<0.05)$. Significantly higher levels of RANKL (151 \%; $p=0.036)$, osteocalcin $(256 \% ; p=0.000)$ and alkaline phosphatase $(152 \% ; p=0.000)$ were observed in premenarcheal adolescents with idiopathic scoliosis, compared with the control group.

Additionally, in postmenarcheal girls with scoliosis the levels of FSH (86 \%, $p=0.022)$, LH $(72 \% ; p=0.000)$, estra$\operatorname{diol}(61 \% ; p=0.000)$ and progesterone $(68 \% ; p=0.000)$ were lower compared with postmenarcheal healthy girls. All differences were statistically significant $(p<0.05)$. In postmenarcheal girls with scoliosis the levels of oestrone were slightly lower $(96 \% ; p=0.733)$ and oestriol $(100 \% ; p=0.872)$ did not differ from that in postmenarcheal healthy girls and there was no statistical significance. Significantly higher levels of RANKL (163\%; $p=0.047)$, osteocalcin $(134 \%$; $\mathrm{p}=0.000)$ and alkaline phosphatase $(117 \% ; p=0.122)$ were observed in postmenarcheal adolescents with idiopathic scoliosis, compared with the control group.

In postmenarcheal girls with AIS compared to premenarcheal adolescents with AIS, higher levels of FSH (104\%), LH (204\%), oestradiol (231\%), oestrone (120\%), oestriol (101\%), progesterone (101\%) and RANKL (137\%) as well as lower level of osteocalcin (59\%) and alkaline phosphatase $(65 \%)$ were observed. The results are summarized in Table 1 and presented in Figs. 1, 2, 3, 4, 5, 6, 7, 8 and 9.

\section{Discussion}

Female puberty is determined by the secretion rhythms of pituitary (FSH and LH) and ovarian hormones (oestrogens and progesterone). Reaching puberty is preceded by a period of pubescence, which varies depending on the individual and

Table 1 Mean values of parameters determined in the studied groups of girls, compared with the $t$-test for independent variables

\begin{tabular}{|c|c|c|c|c|c|c|}
\hline \multirow[t]{2}{*}{ Parameter } & \multicolumn{2}{|l|}{ Premenarcheal } & \multirow[t]{2}{*}{$\mathrm{p}$-value } & \multicolumn{2}{|l|}{ Postmenarcheal } & \multirow[t]{2}{*}{ p-value } \\
\hline & $\begin{array}{l}\text { Control }(n=50) \\
\text { Mean } \pm \text { SD }\end{array}$ & $\begin{array}{l}\text { Scoliosis }(n=50) \\
\text { Mean } \pm \text { SD }\end{array}$ & & $\begin{array}{l}\text { Control }(n=50) \\
\text { Mean } \pm \text { SD }\end{array}$ & $\begin{array}{l}\text { Scoliosis }(n=50) \\
\text { Mean } \pm \text { SD }\end{array}$ & \\
\hline Age [years] & $12.4 \pm 0.9$ & $12.6 \pm 1.1$ & & $13.8 \pm 0.5$ & $14.6 \pm 1.9$ & \\
\hline $\mathrm{BMI}\left[\mathrm{kg} / \mathrm{m}^{2}\right]$ & $19.4 \pm 0.12$ & $21.3 \pm 0.23$ & & $19.2 \pm 0.51$ & $21.5 \pm 0.28$ & \\
\hline $\mathrm{FSH}[\mathrm{mIU} / \mathrm{mL}]$ & $7.43 \pm 2.43$ & $6.58 \pm 2.75$ & 0.167 & $7.95 \pm 2.46$ & $6.84 \pm 2.33$ & $0.022 *$ \\
\hline LH [IU/mL] & $8.02 \pm 2.84$ & $7.68 \pm 4.39$ & 0.646 & $21.71 \pm 3.76$ & $15.7 \pm 5.45$ & $0.000 *$ \\
\hline Oestradiol [pg/mL] & $43.19 \pm 20.09$ & $16.76 \pm 7.10$ & $0.000^{*}$ & $63.73 \pm 12.63$ & $38.78 \pm 16.09$ & $0.000 *$ \\
\hline Oestrone $[\mathrm{pg} / \mathrm{mL}]$ & $22.76 \pm 11.44$ & $22.87 \pm 10.06$ & 0.959 & $28.77 \pm 18.14$ & $27.49 \pm 19.24$ & 0.733 \\
\hline Oestriol [ng/ml] & $1.08 \pm 0.29$ & $1.09 \pm 0.26$ & 0.880 & $1.10 \pm 0.30$ & $1.10 \pm 0.24$ & 0.872 \\
\hline Progesterone $[\mathrm{ng} / \mathrm{mL}]$ & $0.75 \pm 0.37$ & $0.81 \pm 0.39$ & 0.394 & $1.20 \pm 0.30$ & $0.82 \pm 0.53$ & $0.000 *$ \\
\hline Osteocalcin [ng/ml] & $23.82 \pm 13.60$ & $61.12 \pm 21.83$ & $0.000^{*}$ & $22.16 \pm 12.08$ & $36.03 \pm 21.35$ & $0.000 *$ \\
\hline RANKL $[\mathrm{pg} / \mathrm{ml}]$ & $1135.0 \pm 977.5$ & $1717.8 \pm 1668.9$ & $0.036^{*}$ & $1758.1 \pm 1364.1$ & $2346.9 \pm 1555.9$ & $0.047^{*}$ \\
\hline Alkaline Phosphatase [U/L] & $268 \pm 136.6$ & $406.2 \pm 109.77$ & $0.000^{*}$ & $226.12 \pm 110.6$ & $264.66 \pm 134.9$ & 0.122 \\
\hline
\end{tabular}

*Statistically significant differences 
Fig. 1 Mean concentration of FSH in the groups of girls studied
Estimated marginal means

Decomposition of effective hypotheses

Vertical bars denote 0.95 confidence intervals

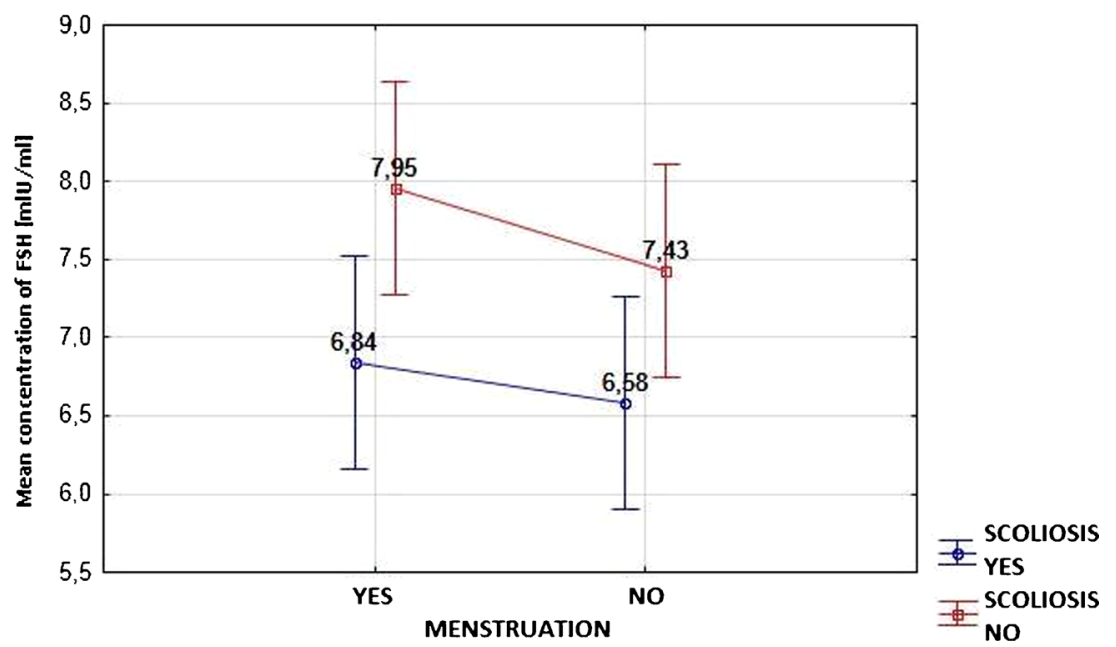

is associated with characteristic changes in a girl's silhouette, growing content of adipose tissue, and increasing levels of female sex hormones. Eventually, all these preparatory stages lead to full puberty, which manifests with menstrual bleeding [31].

Girls between the age of ten and 14 can develop scoliosis, usually idiopathic. The number of hypotheses on the involvement of biochemical, neurological, mechanical, hormonal and genetic factors have been proposed. Oestrogens modulate bone growth and remodeling, and control changes in the structure of cancellous bones. Although oestrogens do not constitute an aetiological factor of AIS, they can influence the progression of spinal deformation, interacting with other factors modulating growth, biomechanics, and structure of bones [32,
33]. Such changes are reflected by decreased stability of cancellous bones, mostly vertebrae, and can be pre-requisite for scoliosis. Therefore, oestrogens can modulate the severity of progression in AIS-related spinal deformation. Moreover, oestrogens are known to influence the differentiation of osteoblasts, and equilibrium between the amounts of collagen and glycoproteins in skeletal tissue. Enhanced bone turnover associated with oestrogen deficiency results from changes in the secretion of cytokines and growth factors by osteoblasts, osteoclasts, and other cells of the skeletal tissue [32, 33]. Loss of oestrogens results in increased bone turnover, with both increased osteoclast and osteoblast activities. Estrogens upregulate genes involved in signal transduction and regulation of transcription such as $\mathrm{IGF}-1$, that regulate osteoblast
Fig. 2 Mean concentration of LH in the groups of girls studied
Estimated marginal means Decomposition of effective hypotheses Vertical bars denote 0.95 confidence intervals

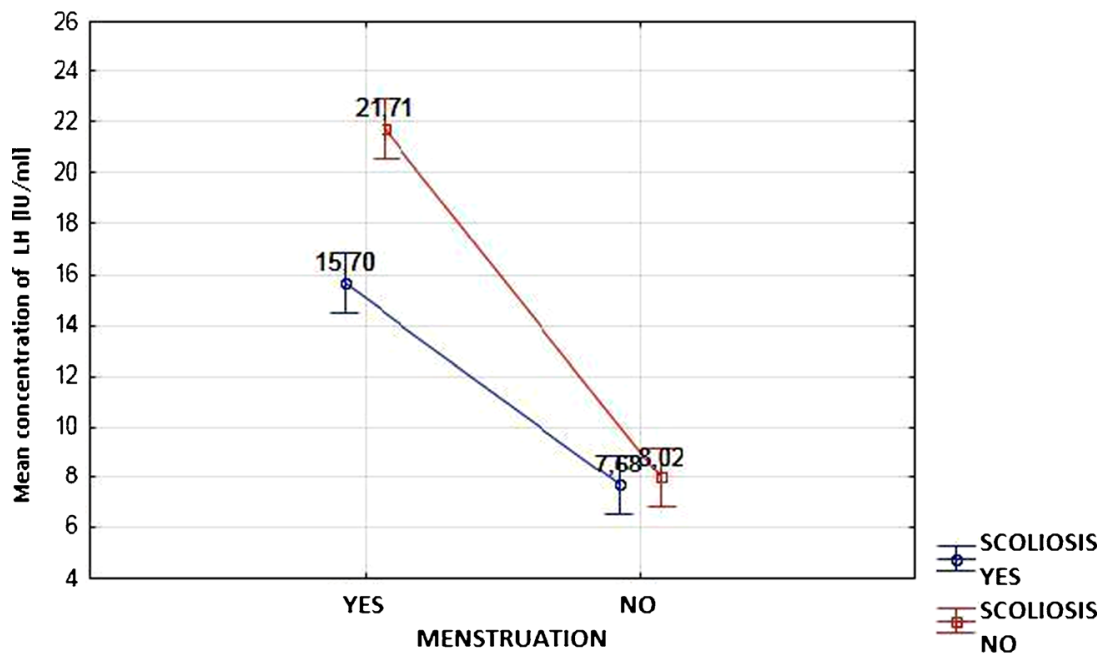


Fig. 3 Mean concentration of oestradiol in the groups of girls studied
Estimated marginal means Decomposition of effective hypotheses

Vertical bars denote 0.95 confidence intervals

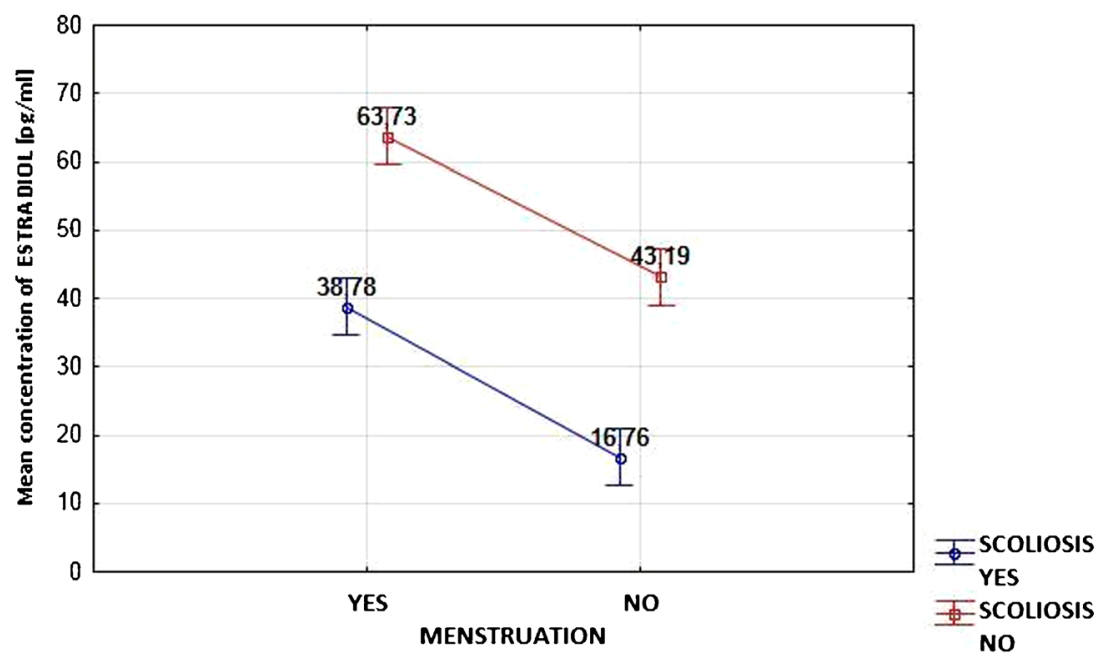

proliferation, differentiation and activity; Fas Ligand (FasL) that induces osteoclast apoptosis; osteoprotegerin (OPG) that inhibits the RANKL pathway; as well as alkaline phosphatase, which is a marker of early osteoblast differentiation and is important in the mineralization of bone. On the other hand, oestrogens downregulate genes involved in immune and inflammatory response including IL-1 as a pro-inflammatory cytokine [25]. In addition, oestrogens modulate the activity of the melatonin receptor and inhibit the synthesis of melatonin. Moreover, they interact with other hormones and biochemical factors, such as calcium-binding protein calmodulin, as well as with other proteins controlling muscle contractility.

In this study, we investigated the potential association between spinal deformation and the levels of female sex hormones, including oestrogens. We assumed that the process of spinal deformation can result from abnormal levels of oestrogens. Furthermore, we hypothesized that the consequences of estrogen deficiency can be observed in both premenarcheal and postmenarcheal girls. Therefore, understanding the role of oestrogens seems vital for explaining the evolution of AIS associated with skeletal growth [24, 29, 34-36].

Our study revealed that the levels of FSH, LH, and estradiol in premenarcheal girls with AIS were markedly lower than in their scoliosis-free peers. Also, the levels of FSH, LH, oestradiol, and oestrone in postmenarcheal girls with scoliosis turned out to be lower than in healthy controls. Delayed menarche results from the later age of beginning puberty can explain these observations. The mean age of girls with AIS
Fig. 4 Mean concentration of oestrone in the groups of girls studied
Estimated marginal means

Decomposition of effective hypotheses Vertical bars denote 0.95 confidence intervals

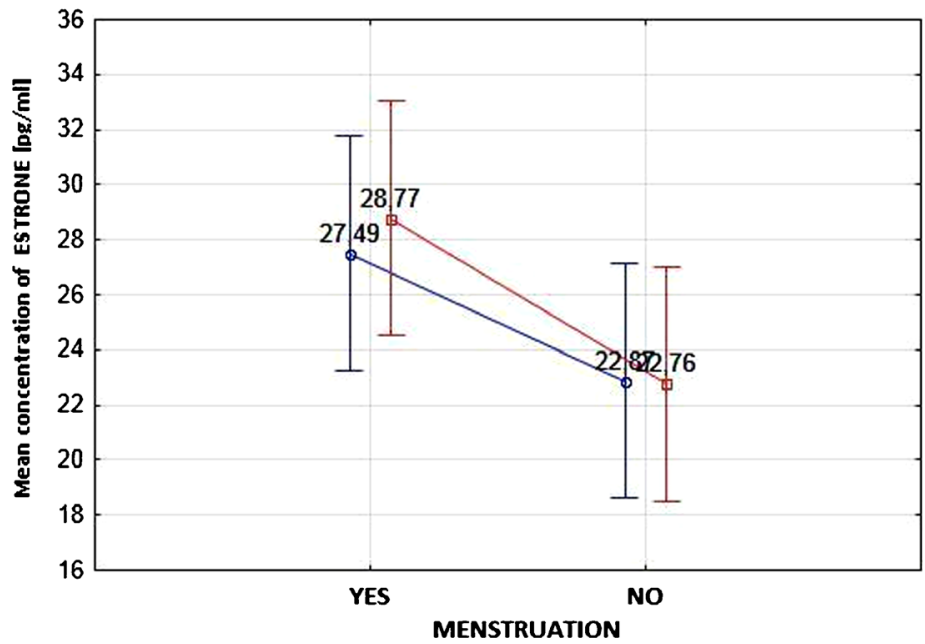

क्षेS SCOLIOSIS 車 $N O$ 
Fig. 5 Mean concentration of oestriol in the groups of girls studied
Estimated marginal means

Decomposition of effective hypotheses

Vertical bars denote 0.95 confidence intervals

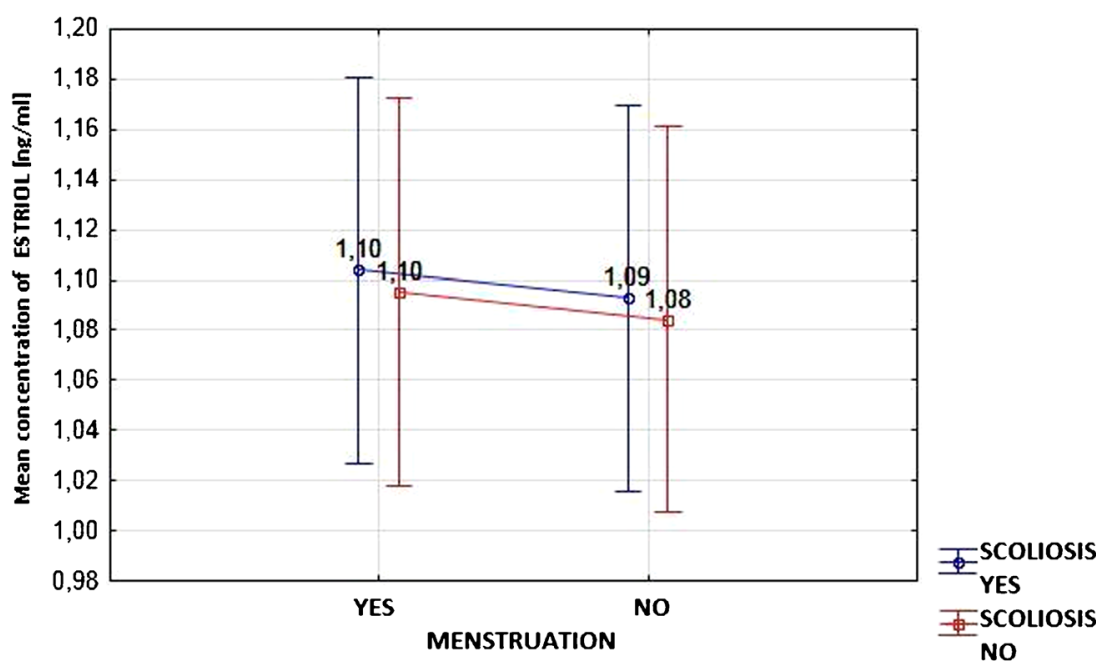

was higher in both pre- and postmenarcheal groups compared to healthy girls. Furthermore, we found that the levels of FSH, LH, oestradioll, and oestrone in premenarcheal girls with AIS were lower than in postmenarcheal patients suffering from this condition. It may be a result of higher level of LH after menarche and stronger modulation of sex hormones production such as oestradiol and progesteron.

Our results on oestradiol level are in contrast with results obtained by Raczkowski [37]. He found no statistical difference in estrogen levels in folicular and luteal phase between girls with scoliosis and healthy girls, but demonstrated increased testosterone level in girls with AIS. The possible cause for the difference between our study and those by Raczkowski [37] may be due to the different study design and number of participants included. The study by Raczkowski included a group of 27 girls (mean age 14.8 years) with scoliosis without division on premenarcheal and postmenarcheal condition and a group of only seven girls without scoliosis (control group; mean age 14.3 years). In our study, a total of 200 girls were included and divided into four groups ( $n=50$ each): pre- and postmenarcheal girls with scoliosis (mean age 12.6 years and 14.6 years, respectively), and pre- and postmenarcheal controls (mean age 12.4 years and 13.8 years, respectively) (as described in the Material and Methods section). We measured oestrogen levels in postmenarcheal girls only once, two to three days following the last day of the menstrual period (follicular phase). The level of testosterone was not determined in our study.
Fig. 6 Mean concentration of progesterone in the groups of girls studied
Estimated marginal means

Decomposition of effective hypotheses

Vertical bars denote 0.95 confidence intervals

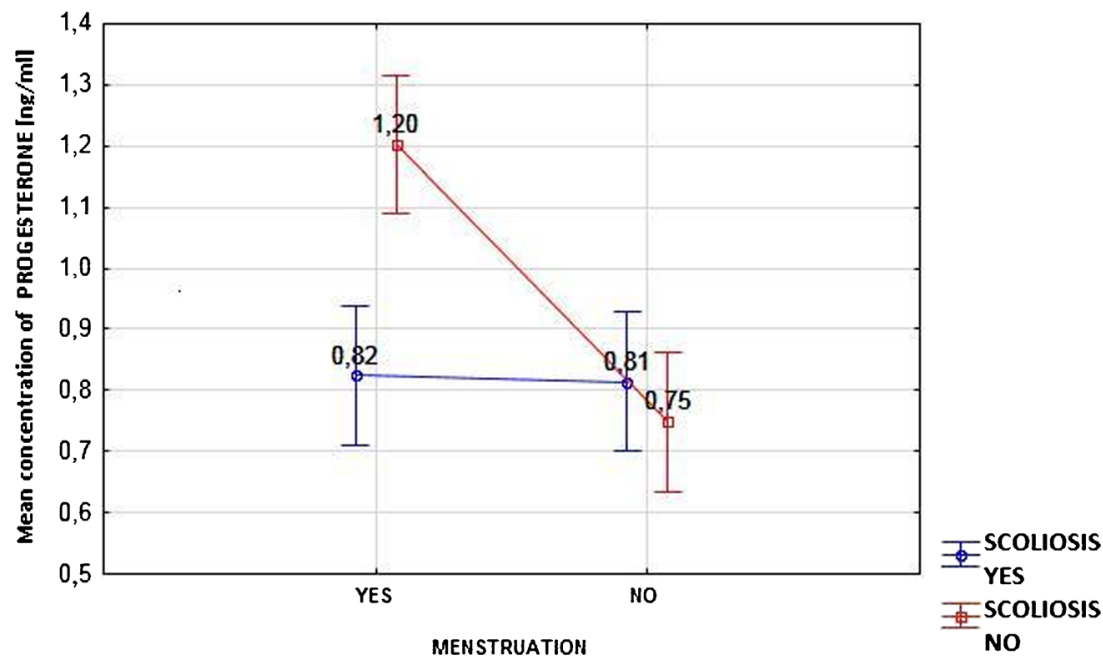


Fig. 7 Mean concentration of osteocalcin in the groups of girls studied
Estimated marginal means

Decomposition of effective hypotheses

Vertical bars denote 0.95 confidence intervals

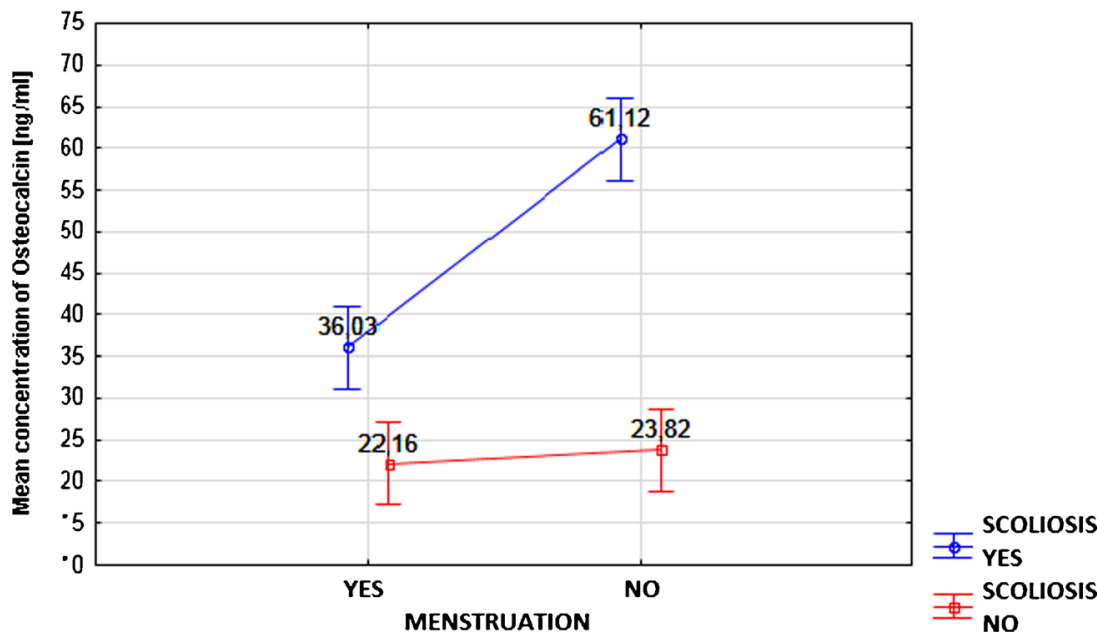

Altered levels of sex hormones can play an important role in the pathogenesis of scoliosis. The levels of FSH, LH, oestradiol, and progesterone can serve both as markers of normal sexual maturation and indices for potential pathologies, e.g. scoliosis. The reasons for decreased levels of the abovementioned hormones are difficult to explain. Nevertheless, the consequences of reduced levels of these hormones should be considered as one of the most important factors involved in the development of scoliosis. Despite marked intergroup differences in the levels of sexual hormones, girls with scoliosis and healthy controls did not differ significantly in terms of age at menarche.

Imbalance in bone formation-bone resorption is observed in AIS, which is characterized by bone loss and leads to curve progress. This process includes the action of RANKL and can be manifested by an increase of osteocalcin and alkaline phosphatase. RANKL is produced by osteoblastic lineage cells, and activated $\mathrm{T}$ cells promotes osteoclast formation, fusion, differentiation, activation, and survival, leading to enhanced bone resorption and bone loss. RANKL expression is modulated by various cytokines (IL-1, IL-6, IL-11), glucocorticoids, and PTH $[26,38]$. It is known that oestrogens inhibit RANKL production, diminishing bone resorption [25]. Osteocalcin is produced by osteoblasts and is widely accepted as a marker of bone osteoblastic activity. Osteocalcin, incorporated into the bone matrix, is released into the circulation from the matrix during bone resorption. Total serum alkaline phosphatase has been used as a biochemical marker
Fig. 8 Mean concentration of RANKL in the groups of girls studied
Estimated marginal means

Decomposition of effective hypotheses

Vertical bars denote 0.95 confidence intervals

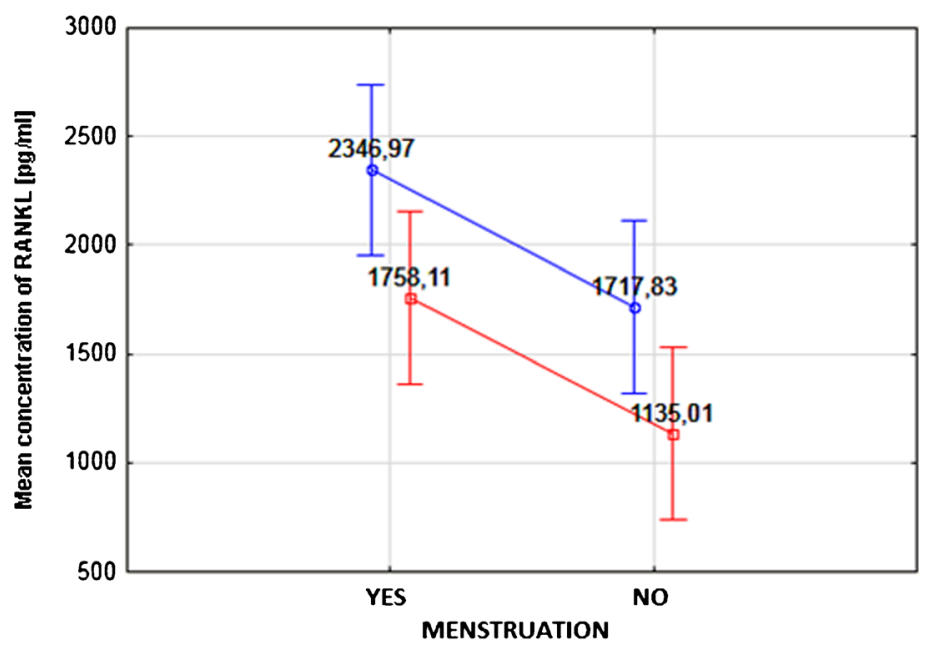

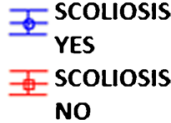


Fig. 9 Mean concentration of alkaline phosphatase in the groups of girls studied
Estimated marginal means

Decomposition of effective hypotheses

Vertical bars denote 0.95 confidence intervals

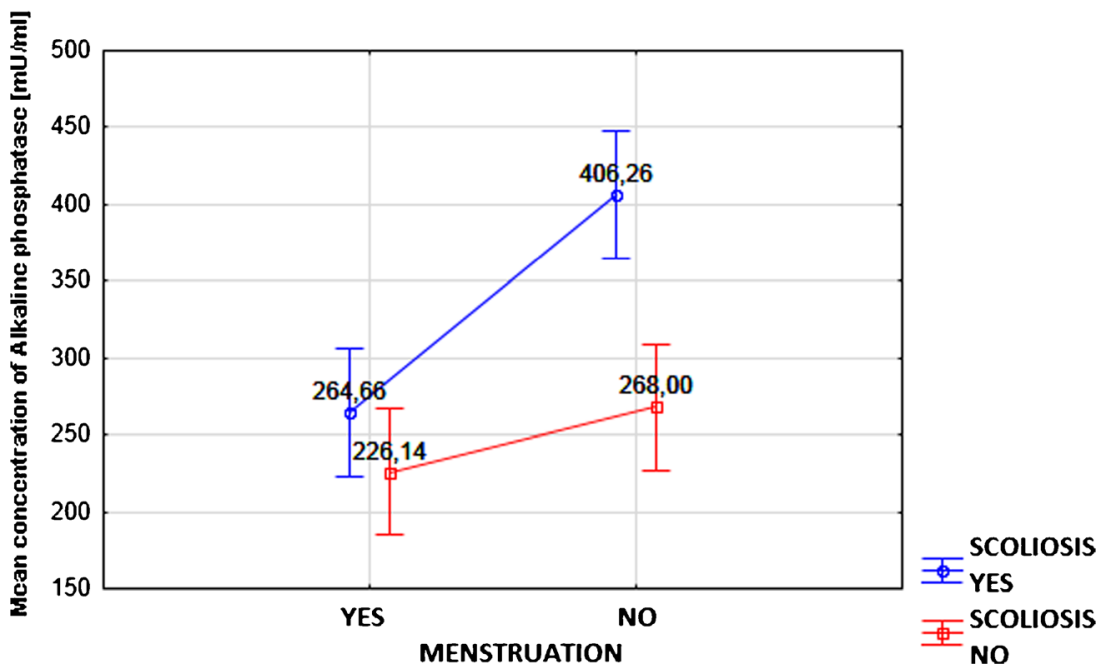

for bone formation to assess osteoblastic activity. Both markers are increased in metabolic bone diseases with increased bone or osteoid formation including osteopenia, osteoporosis, as well as in adolescent idiopathic scoliosis [39-44].

In this study we investigated the levels of osteocalcin and alkaline phosphatase as markers for the bone formation process and RANKL, which is a ligand for osteoprotegerin and functions as a key factor for osteoclast differentiation and activation. Significantly higher levels of RANKL, osteocalcin and alkaline phosphatase were observed in adolescents with idiopathic scoliosis, in pre- as well as postmenarcheal girls, compared with respective control groups. Similar results may be observed in metabolic bone diseases [40, 41, 45]. The lower level of osteocalcin and alkaline phosphatase after menarche, in groups of healthy girls and with AIS, suggest a slowdown in bone resorption, which is normal after puberty, where a gradual lowering of both markers is observed [46]. On the contrary, the higher level of RANKL after menarche, in groups of healthy girls and with AIS suggests that additional processes are involved in regulation of RANKL or level of oestrogen was not enough to modify function of the cytokine. Our results suggests a link between low level of oestrogen and high level of osteocalcin, alkaline phosphatase as well as RANKL.

Decreased levels of oestrogens in both pre- and postmenarcheal girls with scoliosis can be a result of the dysfunction of cells which synthesize these hormones. While the synthesis of FSH and LH was proven normal in both groups of premenarcheal girls, the levels of these hormones in postmenarcheal patients with scoliosis were significantly lower than in the controls. Excessive catabolism and enhanced elimination of oestrogens can be another factor affecting the level of these hormones. We can hypothesise that reduced levels of FSH and $\mathrm{LH}$ observed in girls with AIS cause hypoestrogenism resulting in increased pro-inflammatory cytokines such as IL-1 and IL-6, which increase RANKL concentration and osteoclast activity and bone resorption. As a consequence can be observed a higher level of osteocalcin and alkaline phosphatase. Additionally, the dysfunction of oestrogen-binding plasma proteins and polymorphism of oestrogen receptors cannot be excluded as a cause of reduced oestrogen levels. Impaired interaction between sex steroids and the cellular (especially nuclear) system of signal transduction is another factor which can be involved in the aetiopathogenesis of scoliosis. All the factors mentioned above can act simultaneously, forming a multifactorial environment for development of structural abnormalities of cancellous bone. Our findings suggest the association between the reduced levels of oestrogens and prevalence of scoliosis. The remaining issues, such as the levels of oestrogens and their molecular function in cells during the development of scoliosis still need to be explained.

\section{Conclusions}

1. There is an interdependence between the concentration of estradiol and the development of scoliosis.

2. Determination of estradiol may present diagnostic value in the screening of spinal pathologies associated with idiopathic scoliosis. 
3. Higher levels of RANKL, osteocalcin and alkaline phosphatase may induce bone-remodelling changes leading to osteopenia in patients with AIS.

Acknowledgments The authors would like to thank Katarzyna Wadowska and Zuzanna Mikosza for their excellent technical support.

This study was supported by a grant from the National Science Centre Poland no. N N403 100036

Open Access This article is distributed under the terms of the Creative Commons Attribution License which permits any use, distribution, and reproduction in any medium, provided the original author(s) and the source are credited.

\section{References}

1. Sanders JO, Armet K, Bukata S, Behrooz A, Akbarnia MD (2010) Spinal deformity in metabolic diseases. In Muharrem Yazici MD, George H, Thompson MD (eds) The growing spine: management of spinal disorders in young children. Springer, Berlin Heidelberg, pp 163-176

2. Ahn UM, Ahn NU, Nallamsetty L et al (2002) The etiology of adolescent idiopathic scoliosis. Am J Orthop 31:387-395

3. Lowe TG, Edgar M, Margulies JY et al (2000) Etiology of idiopathic scoliosis: current trends in research. J Bone Joint Surg 82A: $1157-1168$

4. Suh KT, Eun IS, Lee JS (2010) Polymorphism in vitamin D receptor is associated with bone mineral density in patients with adolescent idiopathic scoliosis. Eur Spine J 19(9):1545-1550

5. Altaf F, Gibson A, Dannawi Z et al (2013) Adolescent idiopathic scoliosis. BMJ 346:f2508

6. Burwell RG, Dangerfield PH, Moulton A et al (2011) Adolescent idiopathic scoliosis (AIS), environment, exposome and epigenetics: a molecular perspective of postnatal normal spinal growth and the etiopathogenesis of AIS with consideration of a network approach and possible implications for medical therapy. Scoliosis 6(1):26

7. Burwell RG, Dangerfield PH, Moulton A, Grivas TB, Cheng JC (2013) Whither the etiopathogenesis (and scoliogeny) of adolescent idiopathic scoliosis? Incorporating presentations on scoliogeny at the 2012 IRSSD and SRS meetings. Scoliosis 8(1):28

8. Tang SP, Cheng JCY, Ng BKW et al (2003) Adolescent Idiopathic Scoliosis (AIS): an overview of the etiology and basic management principles. HK J Paediatr (new series) 8:299-306

9. Goldberg CJ, Moore DP, Fogarty EE, Dowling FE (2008) Scoliosis: a review. Pediatr Surg Int 24(2):129-144

10. Burwell RG, Dangerfield PH (2012) Whither the etiopathogenesis (and scoliogeny) of adolescent idiopathic scoliosis? Stud Health Technol Inform 176:3-19

11. Cheung KM, Wang T, Qiu GX et al (2008) Recent advances in the aetiology of adolescent idiopathic scoliosis. Int Orthop 6(32):729734

12. Fendri K, Patten $\mathrm{S}$, Zaouter $\mathrm{C}$ et al (2010) Recent advances in the study of candidate genes for adolescent idiopathic scoliosis. Stud Health Technol Inform 158:3-7

13. Gorman KF, Julien C, Moreau A (2012) The genetic epidemiology of idiopathic scoliosis. Eur Spine J 21(10):1905-19

14. Man GC, Wang WW, Yeung BH et al (2010) Abnormal proliferation and differentiation of osteoblasts from girls with adolescent idiopathic scoliosis to melatonin. J Pineal Res 49(1):69-77

15. Wang WJ, Yeung HY, Chu WC, Tang NL, Lee KM, Qiu Y, Burwell RG, Cheng JC (2011) Top theories for the etiopathogenesis of adolescent idiopathic scoliosis. J Pediatr Orthop 31:S14-S27
16. Chan V, Fong GC, Luk KD et al (2002) A genetic locus for adolescent idiopathic scoliosis linked to chromosome 19p13.3. Am J Hum Genet 71:401-406

17. Gurnett CA, Alaee F, Bowcock A et al (2009) Genetic linkage localizes adolescent idiopathic scoliosis and pectus excavatum gene to chromosome $18 \mathrm{q}$. Spine 34:94-100

18. Vanderschueren D, Vandenput L, Boonen S, Lindberg MK, Bouillon R, Ohlsson C (2004) Androgens and bone. Endocr Rev 25:389-425

19. Justice CM, Miller NH, Marosy B et al (2003) Familial idiopathic scoliosis evidence of an X-linked susceptibility locus. Spine 28: 589-594

20. Weinstein SL, Dolan LA, Cheng JC et al (2008) Adolescent idiopathic scoliosis. Lancet 371:1527-1537

21. Hadley MN (2000) Spine update: genetics of familial idiopathic scoliosis. Spine 25:2416-2418

22. Kruse LM, Buchan JG, Gurnett CA, Dobbs MB (2012) Polygenic threshold model with sex dimorphism in adolescent idiopathic scoliosis: the Carter effect. J Bone Joint Surg Am 94(16):1485-91

23. Mao SH, Jiang J, Sun X, Zhao Q, Qian BP, Liu Z, Shu H, Qiu Y (2011) Timing of menarche in Chinese girls with and without adolescent idiopathic scoliosis: current results and review of the literature. Eur Spine J 20(2):260-5

24. Leboeuf D, Letellier K, Alos N et al (2009) Do estrogens impact adolescent idiopathic scoliosis? Trends Endocrinol Metab 20(4): 147-52

25. Krum SA (2011) Direct transcriptional targets of sex steroid hormones in bone. J Cell Biochem 112(2):401-8

26. Cheung J, Mak YT, Papaioannou S, Evans BA, Fogelman I, Hampson G (2003) Interleukin-6 (IL-6), IL-1, receptor activator of nuclear factor kappaB ligand (RANKL) and osteoprotegerin production by human osteoblastic cells: comparison of the effects of 17-beta oestradiol and raloxifene. J Endocrinol 177(3):423-33

27. Balasch J (2003) Sex steroids and bone: current perspectives. Hum Reprod Update 9(3):207-22

28. Gennari L, Merlotti D, De Paola V et al (2005) Estrogen receptor gene polymorphisms and the genetics of osteoporosis. Am J Epidemiol 161:307-320

29. Kulis A, Zarzycki D, Jaśkiewicz J (2006) Concentration of estradiol in girls with idiophatic scoliosis. Ortop Traumatol Rehabil 8:455459

30. Sambrook J, Russel DW (2001) Molecular cloning: a laboratory manual, 3rd edn. Cold Spring Harbor Laboratory, New York

31. Kurdzielewicz M, Rzepka-Górska I, Głogowska A et al (1999) Wiek menarche i analiza wybranych parametrów biofizycznych w terminie menarche. Ginekol Pol 5:354-358

32. Riggs BL (2000) The mechanisms of estrogen regulation of bone resorption. J Clin Invest 106:1203-1204

33. Riggs BL, Khosla S, Melton LJ 3rd (2002) Sex steroids and the construction and conservation of the adult skeleton. Endocr Rev 23 : 279-302

34. Esposito T, Uccello R, Caliendo R, Di Martino GF et al (2009) Estrogen receptor polymorphism, estrogen content and idiopathic scoliosis in human: a possible genetic linkage. J Steroid Biochem Mol Biol 116(1-2):56-60

35. Jochems $\mathrm{C}$, Islandek U, Erlandsson $\mathrm{M}$ et al (2005) Osteoporosis in experimental postmenopausal polyarthritis: the relative contributions of estrogen deficiency and inflammation. Arthritis Res Ther 7:837-843

36. Letellier K, Azeddine B, Parent S et al (2008) Estrogen cross-talk with the melatonin signaling pathway in human osteoblasts derived from adolescent idiopathic scoliosis patients. J Pineal Res 45(4): 383-93

37. Raczkowski JW (2007) The concentrations of testosterone and estradiol in girls with adolescent idiopathic scoliosis. Neuro Endocrinol Lett 28(3):302-4 
38. Schoppet M, Preissner KT, Hofbauer LC (2002) RANK ligand and osteoprotegerin: paracrine regulators of bone metabolism and vascular function. Arterioscler Thromb Vasc Biol 22(4):549-53

39. Singer FR, Eyre DR (2008) Using biochemical markers of bone turnover in clinical practice. Cleve Clin J Med 75(10):739-50

40. Popa O, Chiru Anton M, Vladoiu S, Manda D, Ianas O (2010) Osteocalcin, OPG and RANKL circulating levels in adolescent idiopathic scoliosis. Endocrine Abstracts 22:106

41. Chiru M (2011) Adolescent idiopathic scoliosis and osteopenia. Maedica (Buchar) 6(1):17-22

42. Sanders JO, Browne RH, McConnell SJ, Margraf SA, Cooney TE, Finegold DN (2007) Maturity assessment and curve progression in girls with idiopathic scoliosis. J Bone Joint Surg Am 89(1):64-73
43. Turan S, Topcu B, Gökçe I, Güran T, Atay Z, Omar A, Akçay T, Bereket A (2011) Serum alkaline phosphatase levels in healthy children and evaluation of alkaline phosphatase z-scores in different types of rickets. J Clin Res Pediatr Endocrinol 3(1):7-11

44. Blumsohn A, Hannon RA, Wrate R, Barton J, Al-Dehaimi AW, Colwell A, Eastell R (1994) Biochemical markers of bone turnover in girls during puberty. Clin Endocrinol (Oxf) 40(5):663-70

45. Yoichi A, Ko I, Nobuyuki T, Tomoyuki S (2013) Relationship between bone density and bone metabolism in adolescent idiopathic scoliosis (AIS). Scoliosis 8:Suppl 2

46. Ambroszkiewicz J, Gajewska J, Laskowska-Klita T (2002) Serum osteocalcin and bone alkaline phosphatase in healthy children in relation to age and gender. Med Wieku Rozwoj 6(3):257-265 